\title{
30 cromatismo
}

en los corales de J. S. Bach:

las notas cromáticas no estructurales entendidas como cromatismos con función tonal (CFT)

Miguel Andrés Pedraza-Gualdrón*

Alejandro Benavides Sotomayor ${ }^{\star \star}$ 


\section{Resumen}

En este artículo de investigación se amplía el concepto de cromatismo dentro de los corales de J. S. Bach, concepto y materiales que son tradicionalmente incluidos en los programas de formación musical a nivel de pregrado. Así, del análisis de los corales surge la discusión que lleva a cuestionar si la clasificación actual de los cromatismos es la que mejor explica cada uno de los eventos cromáticos que ocurren en este repertorio, planteando la tesis de que los cromatismos no estructurales (CNE) en realidad no existen en estos corales, sino que cumplen una función tonal (CFT) que busca establecer, melódica o armónicamente, una nueva estructura diatónica o centro tonal. Así mismo, esta investigación analiza y explica seis casos excepcionales únicos que sirven para corroborar la teoría que se propone al poder agruparse dentro de algunas de las categorías propuestas.

Palabras clave: cromatismo; Bach; corales; función tonal y no estructural

\section{Chromaticism in the J. S. Bach s Chorales: The Nonessential Chromaticism} understood as Chromaticism with Tonal Function (CTF)

\section{Abstract}

This research broadens the concept of chromaticism in I. S. Bach's chorales; concept and materials that are currently included in music training programs at the undergraduate level. Thus, the idea that the Nonessential Chromaticism (NC), which is explained by the traditional theory, virtually doesn't exist in this music. On the contrary, all of these chromatic events have a Tonal Function (СтF) that is not explicit at the moment of their appearance, but it is part of a new chord or a melodic movement that belongs to a new scale or a new tonality. Likewise, this research attempts to explain the only six exceptional cases that serve to corroborate this theory because they can be grouped into some of the categories.

Keywords: chromaticism; Bach; chorales; tonal function and nonessential

Cromatismo nos corais de J. S. Bach: as notas cromáticas não estruturais entendidas como cromatismos com função tonal (CFT)

\section{Resumo}

Esta pesquisa expande o conceito de cromatismo dentro dos corais de J. S. Bach; conceito e materiais que são tradicionalmente incluídos em programas de treinamento de música no nível de graduação. Assim, a partir da análise dos corais surge a discussão que leva a questionar se a classificação atual dos cromatismos é a que melhor explica cada um dos eventos cromáticos que ocorrem nesse repertório, levantando a tese de que os Cromatismos Não Estruturais (CNE) na realidade, eles não existem nesses corais, mas eles preenchem uma Função Tonal (CFT) que procura estabelecer, melodicamente e / ou harmonicamente, uma nova estrutura diatônica ou centro tonal. Da mesma forma, esta pesquisa analisa e explica seis casos excepcionais únicos que servem para corroborar a teoria que se propõe a ser agrupada em algumas das categorias propostas.

Palavras-chave: cromatismo; Bach; corais; função tonal e não estruturais
El término cromatismo y la idea de lo cromático ${ }^{1}$ han sido objeto de múltiples reflexiones y actualizaciones en la historia de la teoría y el análisis de la música de Occidente desde los primeros tratados de armonía de principios del siglo xvIII hasta la definición moderna y más simple del término: el uso de las doce notas que resultan de dividir una octava en doce semitono iguales (Dunsby y Whittall, 2014). Empezando con la teoría de Rameau (1722), la cual ayudó a establecer los fundamentos del sistema tonal, el cromatismo ha transitado por un camino lo bastante ancho y extenso como para haber cambiado lo suficiente en cuanto a forma y contenido; sin embargo, este se ha resistido constantemente a una reformulación absoluta debido, quizás, a su simpleza y sencillez en cuanto a significado y efecto práctico. Su función, en términos generales, ha seguido siendo la misma: extender y enriquecer armónica y melódicamente el espectro diatónico de una estructura de siete notas, añadiéndole las otras cinco: "Esto produce un efecto maravilloso en la armonía, porque la mayoría de los semitonos, no en el orden diatónico mismo generan constantemente disonancias que posponen o interrumpen las conclusiones $[. .$.$] sin$ alterar el orden diatónico [...]" (Rameau, 1971, p. 304).

Su esencia conceptual parece haber permanecido intacta durante siglos, a pesar de haberse movido por los terrenos profundamente teóricos y filosóficos de François-Joseph Fétis, A. B. Marx o Moritz Hauptmann; este último intentó hacer de la progresión tonal un ejemplo armónico de la dialéctica positiva de Hegel, idea que influenció profundamente a Hugo Riemann y su teoría dualista de los acordes, junto con la conceptualización y categorización de sus tres funciones armónicas: tónica, dominante y subdominante. Para este, el cromatismo está ligado a cambios armónicos de color ${ }^{2}$ dentro de lo diatónico (Riemann, 1930, p. 20), ya que enriquece armónicamente una progresión y da pie a la transposición, la que se reinterpretan los intervalos los acordes de una tonalidad en otra: "Todas las relaciones de estas tan sencillas transposiciones se llaman, como la misma escala fundamental, diatónicas, aunque representen el cambio cromático de algunos sonidos fundamentales" (Riemann, 1930, p. 21). Adicionalmente, este hecho abre las puertas a la modulación, debido a que el reordenamiento interválico produce el movimiento de un centro tonal a otro:

Las armonías cromáticas son especialmente agradables si representan una dominante de la siguiente armonía. Esta relación de dominante puede ser utilizada de una manera más severa y también acentuada intencionadamente, efectuando por medio de esta relación y con ayuda de medios rítmicos una verdadera modulación. (Riemann, 1930, p. 235)

Otros teóricos de finales del xix y comienzos del xx, como Arnold Schoenberg, Heinrich Schenker y algunos de sus discípulos, Felix Salzer y Carl Schachter, han abordado el tema del cromatismo con bastante frecuencia, pero sus ideas y teorías no han diferido en mucho del principio ya expuesto; de hecho, parece reiterarse la idea de que lo cromático surge de una ampliación o extensión de la escala diatónica.

Lo cromático entendido como una cualidad del cromatismo, el cual se explicita a través de un movimiento melódico bien

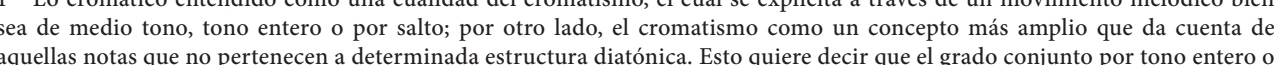
el salto hacia un cromatismo pueden ser entendidos como otros tipos de movimiento cromático dentro del contexto tonal y no Solamente el movimiento cromático por excelenciaie el semitono. Este concepto es distinto en un contexto pancromático, y que
el medio tono es el unico movimiento que se considera comoc cromatico; un ejemplo de ello es la escala cromática, en la que cada

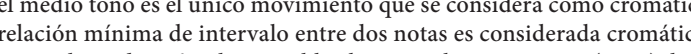
2. En la traducción al español hecha por Ribera y Maneja (1930), la expresión de color aparece entre paréntesis, denotando un
movimiento cromático que cambia la estructura del acorde pero no su funcionalidad. 
Así mismo, todos ellos parecen coincidir, y se hace evidente en lo que aquí llamaremos la tradición de la teoría de la música de Occidente, en que aquellas notas cromáticas que no hacen parte de un acorde deben clasificarse como ornamentales o no estructurales ${ }^{3}$ y su función suele ser la de adornar cromáticamente un evento melódico y armónico, por lo que denominarlas de esta manera implica que son ajenas a un acorde o a una determinada estructura diatónica. Según la etimología de la palabra cromático, que viene del latín chromaticus y del griego kromatikós (kroma), este implica un uso meramente ornmental ya que literalmente se refiere a color y su efecto, y, por lo tanto, "el género cromático varía y embellece el diatónico con sus semitonos, los cuales producen en música el mismo efecto que la variedad de colores en pintura Monlau, 1856, p. 239). En concordancia con esto, podría decirse que el tono alterado busca simplemente adornar un melodía, como afirman Schachter y Aldwell (1989, p. 13), y que, desde esta perspectiva, el evento cromático solo sería tonalmente relevante si hace parte de una estructura acórdica esencial a la progresión.

Sin embargo, en la música de J. S. Bach, estas notas no armónicas parecen ser algo más que meras ornamentaciones y su función resulta esencial en el juego de pasar de un centro tonal a otro. Según Thomas Benjamin (2004) Bach suele tener mucho cuidado al usar estas notas cromáticas, lo cual se ve ratificado en piezas de pequeña envergadura como sus corales a cuatro voces. Es tal el cuidado que podría afirmarse que todos los cromatismos tienen un respaldo armónico evidenciado en una estructura acórdica y aquellos que no están soportados por un acorde, suelen estar incorporados inmediatamente a una nueva tonalidad.

Una definición de cromatismo, que recoge lo que muchos otros teóricos han expuesto acerca del concepto, es la de William Mitchell (1962), quien, buscando rompe el paradigma que considera al cromatismo la simple suma de "7 notas más otras 5", asume, más bien, que el sistema diatónico y lo cromático actúan de forma cooperativa, en donde el primero representa el orden estructural y el segundo la difusión de las posibilidades tonales (p. 2).

\section{ar}

Ista perspectiva resulta esencial para el presente estudio, ya que asume que la función del cromatismo es la de expandir una tonalidad hacia otras; en este sentido, lo diatónico ejerce una fuerza centrípeta que hace que todos los grados de una escala tiendan hacia un centro, mientras que lo cromático, de carácter centrífugo, invita a una reinterpretación de los mismos grados en función de un nuevo centro tonal (Mitchell, 1962, p. 9).

Este estudio revelará que en los corales de Bach todos los eventos cromáticos pertenecen a una de las siguientes ategorías: 1) cromatismo estructural (CE) y 2) cromatismo con función tonal (СFт). La primera se refiere a aquellas notas cromáticas que hacen parte de un acorde con el fin de enfatizar un grado de la escala (dominantes secundarias) o de generar un cambio de centro tonal (modulación) La segunda categoría involucra a los cromatismos que, sin pertenecer a un acorde, logran generar un cambio de centro tonal, lo cual se evidencia en una nueva escala que bien puede ser pasajera ${ }^{5}$ (sin cadencia) o definitiva (con cadencia). Dentro de la teoría tradicional, estas notas pertenecientes a la segunda categoría suelen ser agrupadas, independientemente de su función o estilo, como cromatismos no estructurales; sin embargo, como veremos, este estudio explicará, a través de la revisión de todos los corales de Bach ${ }^{6}$, cómo ningún cromatismo carece de alguna función armónica o tonal.

Además, y como parte final de este estudio, se incluirá el análisis de seis únicos corales en los que se encuentran eventos cromáticos que, en principio, parecen no encajar plenamente en ninguna de estas dos categorías propuestas y que, por lo tanto, podrían ser considerados excepciones. Sin embargo, se demostrará que estas supuestas excepciones lo que hacen es confirmar que Bach tiene un cuidado excesivo con los cromatismos, ya que los procedimientos y las técnicas utilizadas en estos seis casos especiales pueden considerarse variantes de alguna de las dos categorías, las cuales están conectadas con el planteamiento compositivo de cada coral.
Como parte de las dos grandes categorías, cromatismo estructural (CE) y cromatismo con función tonal (CFT), se proponen tres subcategorías según el movimiento melódico-interválico involucrado, es decir, el tipo de gesto cromático implicado (véase la figura 1). Estas subcategorías son: 1) cromatismo por inflexión (CI), el cual implica un movimiento de medio tono hacia una nota con el mismo nombre pero alterada (e.g. do-do\#); 2) cromatismo por grado conjunto (GGC), que presenta un movimiento melódico, sea semitono o tono entero, hacia una nota cromática adyacente (e.g. C: si-do\# o sol-fä\#); y 3) cromatismo por salto (cs), el cual conlleva un movimiento interválico distinto al de grado conjunto (e.g. C: do-fät). Esta organización pone en evidencia que lo cromático no está atado necesariamente al movimiento melódico de medio tono que tradicionalmente ha sido entendido como esencial al concepto de cromatismo, sino que este se integra a la idea general del concepto, la cual es interpretada como una forma de expansión tonal de las estructuras diatónicas. Además, y como conclusión preliminar, se evidenciará que el cGc es el procedimiento más adecuado y recurrente para generar el CFT, debido a que es el movimiento más sutil que permite transitar de una tonalidad a otra a través de la transformación de una escala en otra. Los otros dos movimientos (CI y cs) suelen ser mucho más explíitos y contundentes en el proceso cromático, por lo que resulta más adecuado usar el $\mathrm{CB}$.

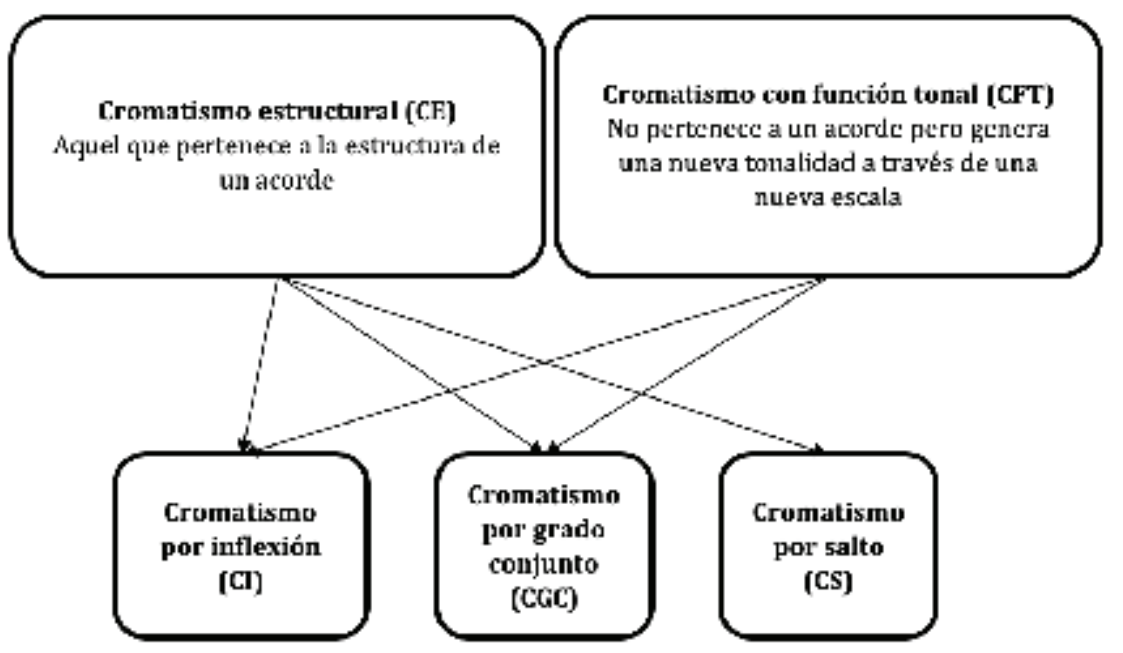

Figura 1. Cromatismo estructural (CE) y cromatismo con función tonal (CFT) $y$ las tres subcategorías CI, CGC $y$ CS

Tabla 1. Convenciones usadas en las gráficas de análisis de los corales

\begin{tabular}{|c|l|c|l|}
\hline CE & Cromatismo estructural & P & Nota de paso \\
\hline CFT & $\begin{array}{l}\text { Cromatismo con función } \\
\text { tonal }\end{array}$ & PA & $\begin{array}{l}\text { Nota de paso } \\
\text { acentuada }\end{array}$ \\
\hline CI & Cromatismo por inflexión & B & Bordado \\
\hline SC & Semicadencia & S & Suspensión \\
\hline CD & Cadencia deceptiva & A & Anticipo \\
\hline
\end{tabular}


Así mismo, Schoenberg, en su Tratado de armonía, si bien hacen unas disquisiciones más profundas sobre las "notas extrañas" ${ }^{10}$ no hacen ninguna diferenciación especial entre las diatónicas y las cromáticas, ya que entienden que su función ornamental no es otra "que una forma melódica simple", por lo que ven como algo natural "que las notas de paso puedan extraerse de la escala cromática" (2004, p. 404). De esta manera, Schoenberg no parece atribuirle ningún valor distinto al de la ornamentación melódica, ni en el capítulo denominado "Sonidos 'extraños a la armonía", ni en el capítulo precedente sobre armonización de corales.

Un intento más reciente por profundizar en las notas no armónicas (sean diatónicas o cromáticas), e influenciado profundamente por Schoenberg, lo hace Timothy Willingham en su tesis doctoral (2013); allí, demuestra cómo muchas de estas notas pueden tener implicaciones armónicas si son entendidas como posibles extensiones del acorde: novenas, oncenas, trecenas, a la luz de teorías modernas en las que el acorde no solo se compone de la tríada básica, sino que puede tener adiciones por terceras. Sin embargo, el teórico no establece diferencia alguna entre lo diatónico y lo cromático, limitando su hipótesis a la idea de reinterpretar las notas no armónicas como si lo fueran pero desde una perspectiva acórdica contemporánea. Así, con estos referentes, se presenta a continuación una serie de ejemplos en los que las notas extrañas cromáticas cumplen con una función tonal y no son simples ornamentaciones o colores melódicos.

En la gráfica 3 se muestran las frases cuatro y cinco del coral 13 en la menor, Allein zu dir, Herr Jesu Christ, en el que aparece una secuencia melodica y armónica al inicio de la quinta frase. Allí pueden verse varias notas cromáticas que no pertenecen a la tonalidad en la que se hizo la cadencia de la cuarta frase (cadencia auténtica imperfecta en la menor) ni en la tonalidad en la que termina la siguiente (semicadencia en re menor). En el mismo fragmento se puede notar un procedimiento melódico secuencial del bajo, que empieza justamente en la cadencia en la menor; este movimiento por grados conjuntos ascendentes, a través del uso de la escala menor melódica (fa\#-sol\#-la), continúa en los siguientes cuatro tiempos del inicio de la siguiente frase, pero en dos tonalidades distintas: sol mayor y mi menor. Así, el fa\# de la anacrusa de la quinta frase es una nota cromática que inicialmente, parecería dirigirse a sol\# para continuar en la tonalidad de la meno sin embargo, al llegar al sol natural, el efecto que se produce es un cambio en la tonalidad. Por consiguiente, este fä debe ser tratado como una nota de paso dentro de sol mayor, es decir, como un cromatismo con función tonal (СFT) Ya que no puede considerarse una nota cromática de paso dentro de la menor, puesto que esta tonalidad desaparece con la llegada de la subtónica (sol natural), la cual es inmediatamente reinterpretada como la nueva tónica, aunque solo sea de forma pasajera.

10 Otra forma de llamar a estas notas no armónicas es la de "notas extrañas", por lo que Schoenberg
insiste en que "no hay, pues, sonidos extraños a la armonía, sino simplemente sonidos extraños insiste en que "no hay, pues, sonidos extraños a la armonía, sino simplemente sonidos extraños al
sistema armónico" (Schonberg, 2004, p. 385), ya que "la armonia es a la simultaneidad sonora" (p. 381).

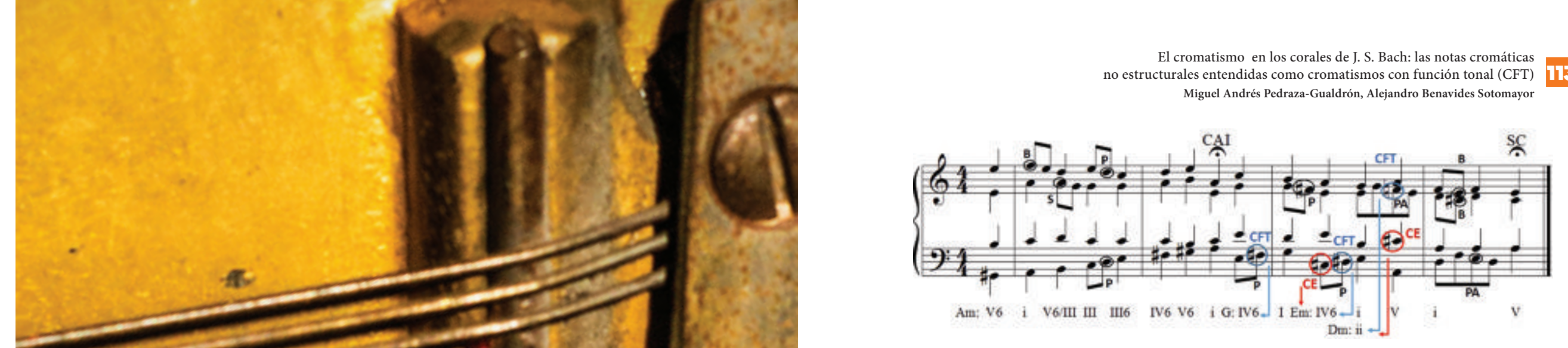

Gráfica 3. Frases cuatro y cinco del coral 13 en la menor: cromatismos con función tonal (CFT)

Este proceso está apoyado armónicamente por los acordes de do mayor y so mayor, que con la sensible de paso permiten entender el enlace armónico IV6-I en sol mayor, lo cual se ratifica con el movimiento melódico de la contralto (solfa\#) que solo es explicable dentro de esta tonalidad, ya que como parte de la menor habría que aceptar que la escala implicada no es tonal sino modal (la dórico).

Luego del fugaz paso por sol mayor la secuencia sigue su curso hacia mi menor, ya que el bajo ejecuta el mismo movimiento melódico ascendente: do\#re\#-mi. De estas notas, las dos primeras se deben considerar cromáticas, ya que no pertenecen a la tonalidad precedente; sin embargo, la primera es un CE que hace parte del acorde de la mayor, mientras que la segunda es un CFT que, dentro de la tonalidad de mi menor, no conforma una nueva armonía, pero sí determina el giro tonal hacia este nuevo centro, actuando como la sensible de paso en el enlace IV6-i.

A continuación se mostrarán distintos ejemplos de los corales en los que aparecen eventos de las dos categorías, pero apoyados en las tres subcategorías que fueron expuestas en la introducción de este escrito y que dan cuenta del movimiento melódico-interválico para abordar la nota cromática: cromatismo por inflexión (CI), cromatismo por grado conjunto (CGC) y cromatismo por salto (Cs) Estas subcategorías buscan evidenciar cómo el cGC es el procedimiento melódico predilecto para generar los СFт, ya que en el caso del cr lo que suele ocurrir es un movimiento armónico que, por lo general, hace que un acorde de tónica se transforme en uno de dominante; $y$ en el cs el movimiento interválico suele representar por sí solo un cambio armónico y no melódico, por lo que su aparición siempre ilustrará un CE y nunca un CFT.

\section{Cromatismo por inflexión}

El movimiento cromático que involucra una nota diatónica seguida inmediatamente de su propia alteración (fa-fä) es lo que se conoce como inflexión cromática. Este movimiento, también llamado semitono cromático por Schachter, difiere del semitono diatónico en el que las dos notas involucradas son parte de la estructura diatónica (Schachter y Aldwell, 1989, p. 13)."1 Además, una vez se genera la alteración cromática, el movimiento suele continuar en la misma dirección con la resolución del

11 Schachter no ofrece una definición clara de semitono diatónico, ya que este, cuando se compara con el
1.

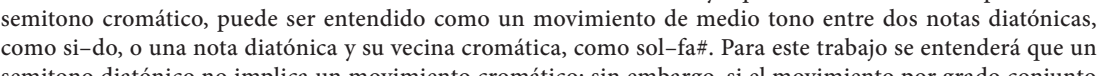
semitono diatónico no implica un movimiento cromático; sin embargo, sie movimiento por grado conjunto
involucra un cromatismo, asi este no sea una inflexión cromática, si s e considerará movimiento cromatitico. 
cromatismo en la siguiente nota diatónica (Benjamin, 2004, p. 77). Esto significa que el cromatismo por inflexión tiene tres momentos: nota diatónica inicial (fa)cromatismo por inflexión (fä)-nota diatónica resolutiva (sol).

En los corales a cuatro voces de Bach esta conexión cromática entre dos alturas diatónicas suele involucrar un nuevo acorde, de manera que este cromatismo implica la aparición de una nueva dominante en la que la nota alterada es parte de una triada o de un acorde con séptima, y no un simple ornamento melódico que, según la teoría tradicional, se denominaría "cromatismo de paso". Además, cuando el movimiento cromático es ascendente, este actúa como una sensible como se muestra en la grífica 1 (c. 2, t. 2, bajo) y en la gráfica 2 (c. 1, t. 2, bajo). En cambio, si el movimiento es descendente, la nota alterada suele ser la séptima de un acorde de dominante $\mathrm{o}$ la quinta de una triada disminuida (gráfica 1: c. 2, t. 2, contralto y gráfica 4: c. 1, t. 3, bajo.

La primera frase del coral 6 en fa mayor, Christus, der ist mein Leben, es un claro ejemplo de este fenómeno. Allí la voz del bajo inicia con un movimiento descendente por grados conjuntos en el que se incluye un cromatismo por inflexión que parte desde la tónica y que termina en la dominante. La nota cromática en cuestión es la transformación del séptimo grado de la escala (sensible) en la séptima de un acorde de dominante que se dirige al sexto grado. La gráfica 4 muestra este movimiento melódico completo (mi-mib-re), en el que el mib es la séptima de una dominante secundaria al IV.

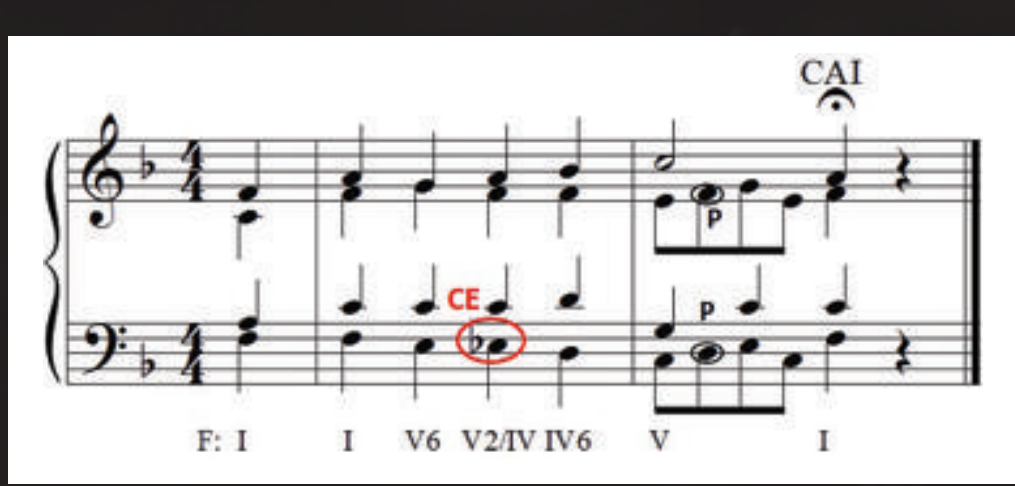

Gráfica 4. Coral 6, primera frase: cromatismo por inflexión descendente

Otro ejemplo es el que ocurre en la cuarta frase del coral 9 en sol mayor Ermuntre dich mein schwacher Geist, en la que se destaca un movimiento cromático ascendente del bajo que involucra dos cromatismos por inflexión que, a su vez, generan dos dominantes secundarias: V65/iv y V65/V (gráfica 5). Allí se puede ver cómo el primer movimiento cromático se enlaza directamente con el segundo, creando un movimiento por semitonos que va desde el fa\# hosta $\mathrm{cl}$ natural. Este movimiento recuerda al movimiento de una escala cromática, pero dentro de este marco tonal-diatónico no todas las notas pueden ser considerada cromatismos, ya que algunas pertenecen a la escala de mi menor.

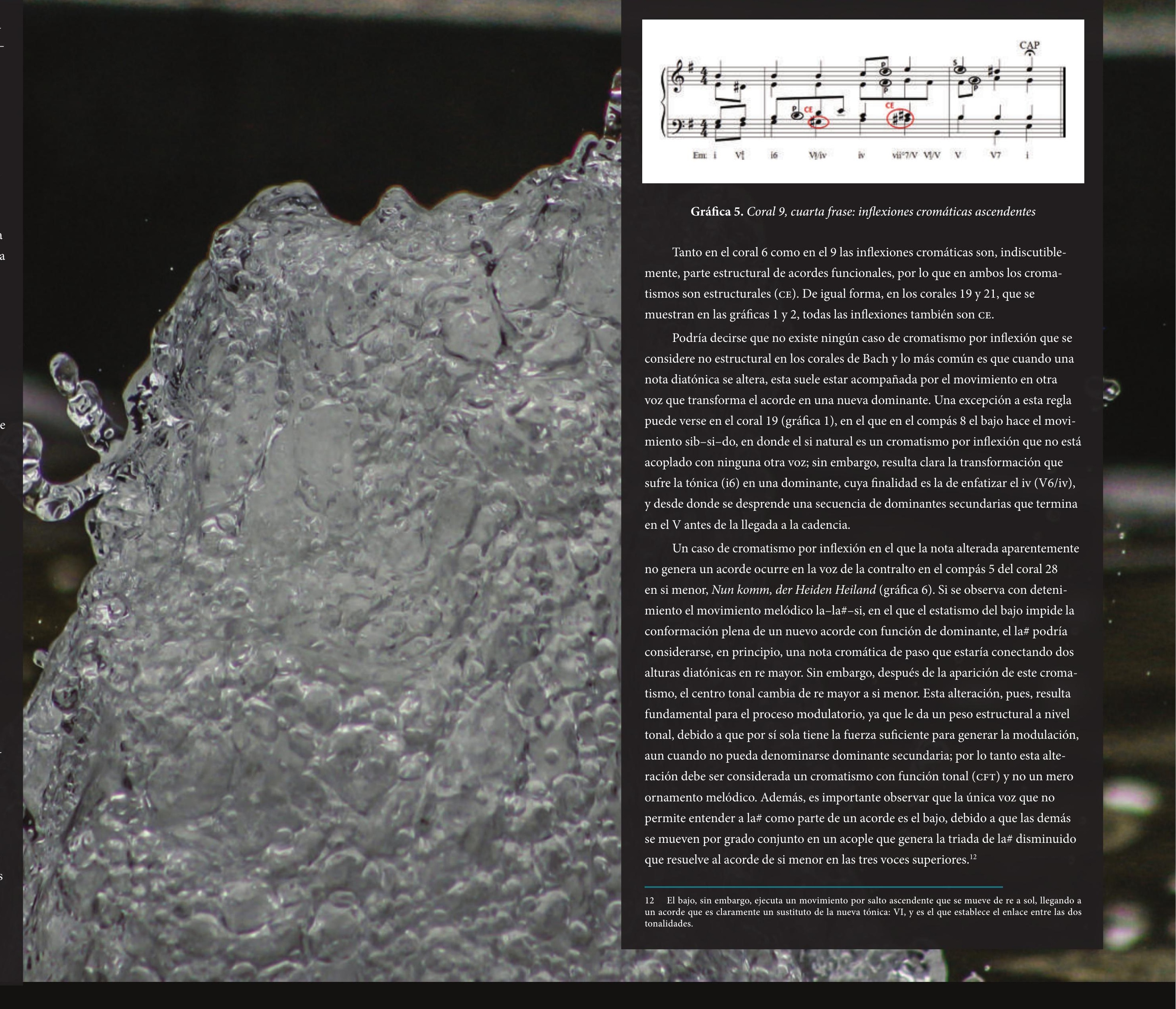


Según el plan propuesto estaría faltando la dominante secundaria del vi (fa\# menor), la cual ocurre en el penúltimo calderón antes de la cadencia final en la tónica. Sin embargo, en el calderón 7 es donde aparece el acorde de sol mayor con séptima que funciona como dominante de do mayor, tonalidad que no se relaciona directamente con la mayor, ni es un giro tonal usual de la época; pero la realidad es que en esta zona desarrollativa el movimiento por grados conjuntos con dominantes secundarias es llevado a su punto máximo, ya que aquí se ejecuta un movimiento que podría interpretarse de la siguiente forma: V/IIIb (do mayor) y V/ii (si menor). Esta última dominante, sin embargo, no resuelve a un acorde menor sino a uno semidisminuido en segunda inversión con séptima, el cual funciona como un préstamo modal de la paralela menor (la menor) y que perfectamente se relaciona con la dominante del IIIb que también es un préstamo modal. En conclusión, el acorde en cuestión respalda el proceso de dominantes secundarias consecutivas expuesto durante todo el coral, pero añade el detalle de enfatizar un grado que está relacionado con la paralela, de la misma manera que ocurrió con los acordes cromáticos de la frase precedente en mi mayor, pero que tiene acordes de la paralela menor."

\section{Cromatismo por grado conjunto}

A diferencia del cromatismo por inflexión, en los corales también se encuentran notas cromáticas que son abordadas desde una nota adyacente pero que no son una inflexión cromática. Un ejemplo en do mayor sería el movimiento mi-fa\#-sol, en el que el fa\# funcionaría como una aproximación cromática hacia la dominante. Otro ejemplo sería el movimiento do-sib-la, en la que el acorde de tónica se transforma en una dominante del cuarto grado con el fin de enfatizarlo. Este, a diferencia del primer ejemplo y de los cromatismos por inflexión, representa un caso de movimiento cromático que no es un semitono sino un tono entero. En la cuarta frase del cora 5 en sol mayor, An Wasserfliussen Babylon, se pueden encontrar algunos de estos cromatismos (gráica 9). La frase inicia con do mayor, acorde común que sirve para modular de sol mayor a do mayor, debido a la aparición reiterada del fa natural como parte de un acorde de dominante. Luego aparece un fa\# en la contralto que genera el regreso a sol mayor antes de dirigirse a re mayor, tonalidad en la que termina la frase. Aquí surgen dos preguntas de análisis: ¿no es este fa\# simplemente una nota de paso cromática dentro de do mayor?, ¿cuál sería la función de esta breve modulación a sol mayor en la que no se presenta ningún acorde de dominante?

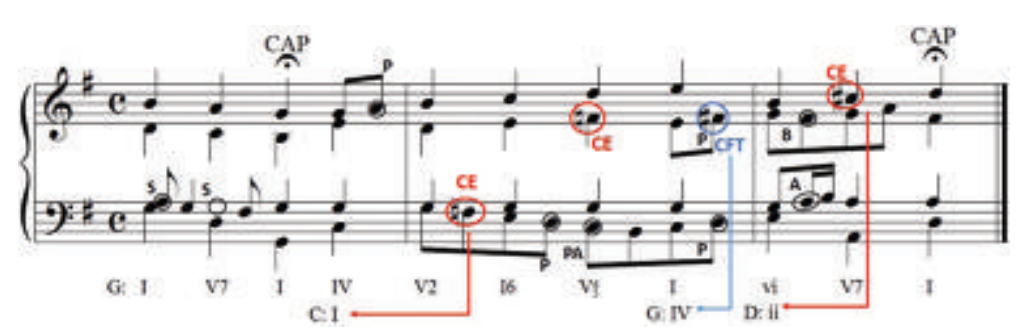

Gráfica 9. Coral 5, final de tercera frase y cuarta frase completa

14 Otra posible interpretación de este acorde sería que fuera un acorde de sexta aumentada (italiana), el cual resolvería
adecuadamente a la dominante de si menor, pero que contaria con una importante particularidad en su escritura, ya que en

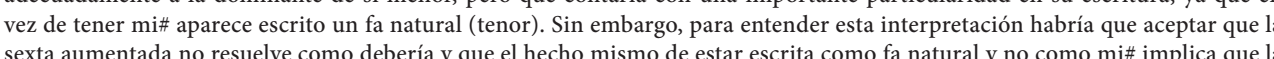
intención no era la de crear una italiana, sino la de una dominante de do mayor. Además, la negación de si menor como posible más posible que esta. Sin embargo, el hecho de poder contar con dos posibilidades "viables" para cifrar el a corde es una muestra más positle que esta. Sin embargo, el hecho de poder contar con dos posibilidads
evidente del cuidado con el que ach trata estos acordes altamente cromaticos.
Esta primera alteración, fa natural, abordada por grado conjunto se considera un cromatismo estructural (CE), el cual, a diferencia del fa\# que aparece posteriormente en la contralto, sí conforma un acorde. De hecho, esta alteración (fä) se comporta como una nota de paso entre los acordes de do mayor (IV) y mi menor (vi) dentro de sol mayor. Se trata entonces de la sensible de paso que permite una relación progresiva entre estos dos acordes, soportada, además, por la nota re en el bajo que, acoplada con la contralto, sugiere el acorde de dominante: re mayor. Por lo tanto, la etiqueta "nota de paso cromática", que se usaría en un análisis que no contemplaría a sol mayor como un posible centro con la función de conectar a do mayor con re mayor, no da cuenta de su verdadera función tonal (CFT), la cual consiste en conectar a do mayor con re mayor de la manera más sutil posible: tonalidad puente o de paso, tonalidades que, según el estilo y la época, no están relacionadas cercanamente. ${ }^{15}$

Otro ejemplo que ilustra cromatismos por grado conjunto está en el coral 13, ya referenciado (gráfica 3). Allí, al final del compás 2 , el fa\# genera la modulación hacia sol mayor, mientras que el re\#\# del siguiente compás cumple la misma función pero hacia mi menor. Estos dos ejemplos dan cuenta de cromatismos con función tonal (CFT) y, además, funcionan como sensi-

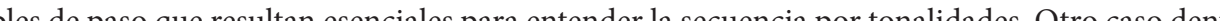
del mismo coral ocurre en el último tiempo del tercer compás (gráfica 10), donde aparecen dos cromatismos por grado conjunto sobre la dominante de re menor: do\# en el tenor y fa natural

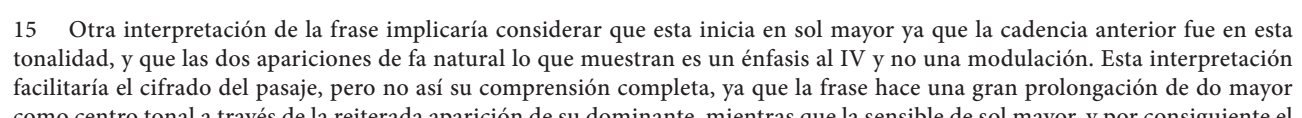

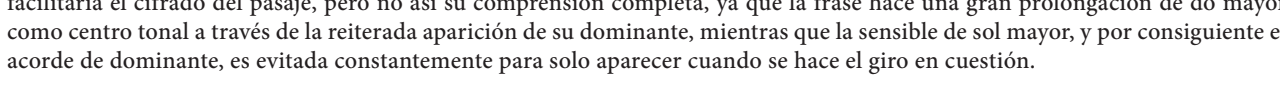

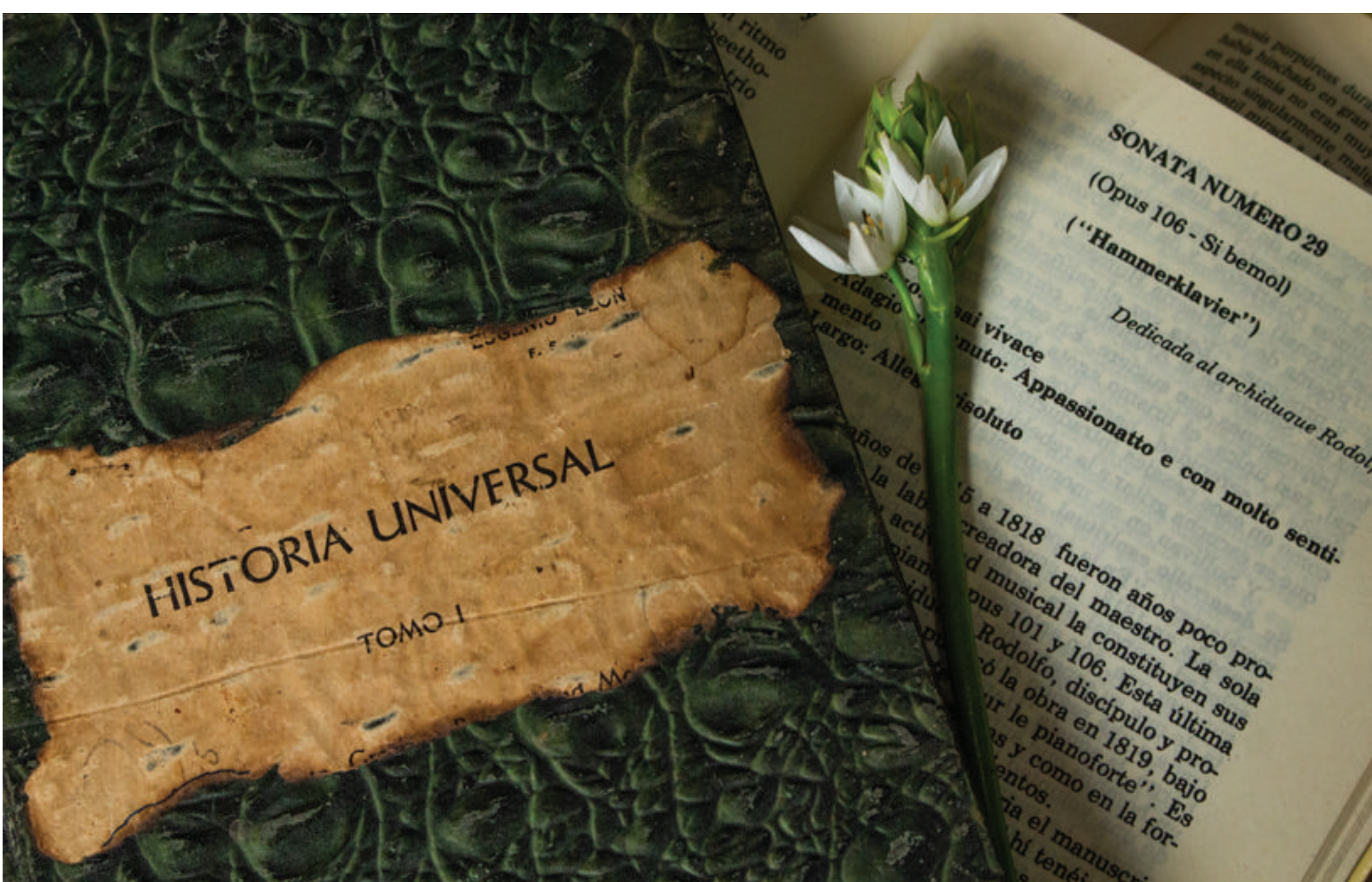


en la contralto. El primero es un CE que hace parte del acorde, mientras que el segundo es un CFT que se mueve por grados conjuntos a una nota del acorde: mi. Sin embargo, en la siguiente gráfica se muestra cómo este fa natural podría ser entendido también como un $\mathrm{CE}$ asumiendo que se presenta no solo un acorde sino dos durante el mismo pulso: uno ornamental (IIIx6) y otro funcional (V). De hecho, una de las formas de ornomentar a b do nante con otro acorde es, precisamente, el tercer grado aumentado que contiene a la sensible.

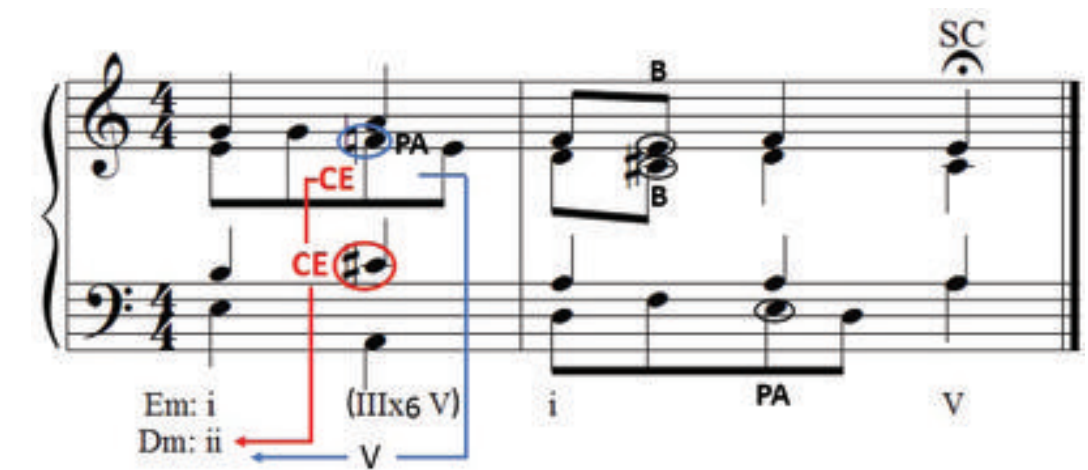

Gráfica 10. Coral 13, fragmento final de la quinta frase: ¿CFT O CE?

\section{Cromatismo por salto}

Teniendo en cuenta que el concepto de cromatismo apunta principalmente al uso de cualquier nota que no pertenece a una determinada escala diatónica, un intervalo melódico distinto al grado conjunto también puede ser considerado un movimiento cromático. Esta manera de abordar una nota alterada es, por supuesto, la menos común dentro de los comportamientos melódicos cromáticos en los corales. En este sentido, Thomas Benjami nos recuerda que Bach es muy cuidadoso en el uso de los cromatismos, "restringiendo su uso a apariciones breves, notas de paso no acentuadas y bordados” (Benjamin, 2004, p. 78). Asi aunque no exista una gran cantidad de ejemplos con este tipo de movimiento cromático, el cual suele ser considerado atípico o extraño, ya que no está asociado al concepto tradicional de cromatismo por semitono, es importante observar algunos ejemplos que dan cuenta de este tipo de movimiento cromático que evidencian el cuidado con el que Bach los manejaba. Además, la totalidad de los casos de cs dan cuenta de alteraciones que hacen parte de una armonía, como es el caso del primer ejemplo que se muestra en la gráfica 11.

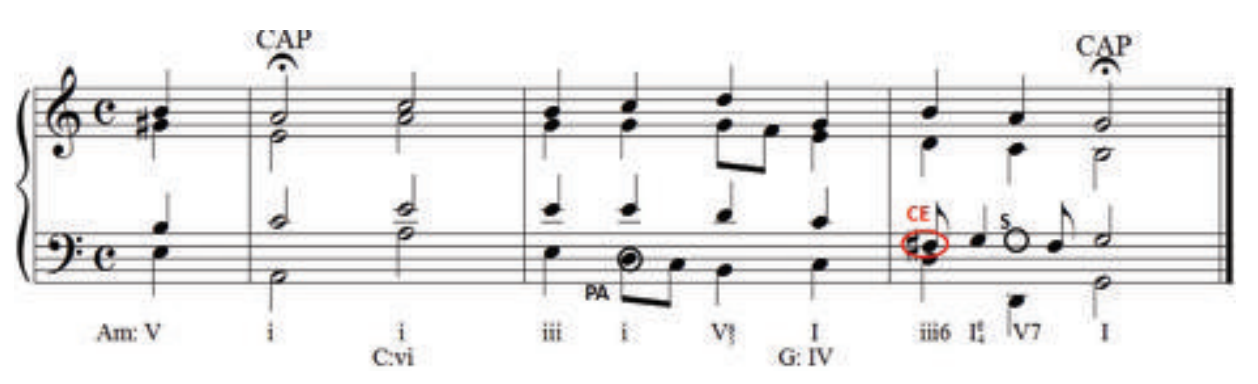

Gráfica 11. Coral 10, cuarta frase: CE por salto de tritono
En la cuarta frase del coral 10 en la menor, Aus tiefer Not schrei' ich zu dir, parece un cromatismo por salto en el que el tenor ejecuta un intervalo de tritono descendente, el cual es compensado inmediatamente con un movimiento de sem tono en la otra dirección. La nota involucrada es un fa\# que no pertenece a la tonalidad del inicio de la frase y que, en cambio, genera una modulación hacia sol mayor, donde se hace la cadencia de la frase. Este intervalo y su resolución elen ser los novinietos mís recurets en recióncon los cuonatinos por 政 nante, el cual debe ser resuelto melódicamente en la dirección contraria. En el ejemplo, la tríada que da soporte al cromatismo es un acorde ornamental (iii6) cuya función es la de adornar, colorear o embellecer a la dominante y, por lo tanto, este fa\# se entiende como un cromatismo estructural (CE). Otros casos similares,

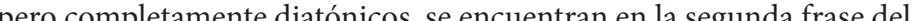
la menor y en la sexta frase del coral 5 en sol mayor, en la que el tenor, en ambos casos, ejecuta un movimiento idéntico al del coral 10

Otro ejemplo de cromatismo por salto lo provee el coral 13, al cual ya se ha hecho rerencia para mostrar cromatismos por grado conjunto estructurales y con función tonal (gráfica 3). En el mismo fragmento (inicio de la quinta frase) se presenta un cromatismo por salto dentro de la secuencia tonal que empieza en la menor y pasa por sol mayor y mi menor (gráfica 12). La breve modulación a mi menor implica un salto de tritono en el bajo que inicialmente parece llegar a una sensible que generaria la dominante secundaria del quinto; sin embargo, este CE (do\#) se dirige a un CFT, de

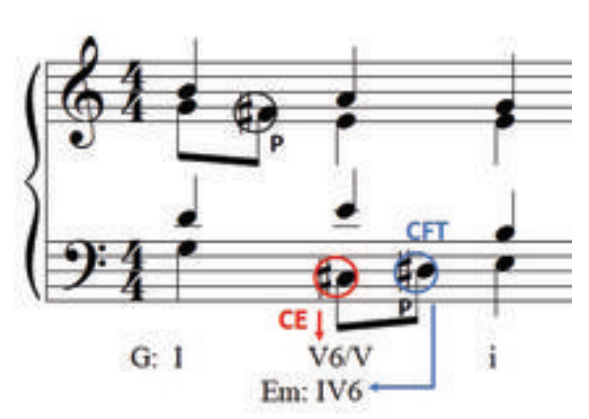

Gráfica 12. Coral 13, fragmento inicial quinta frase

\section{Casos cromáticos excepcionales}

Aunque el objetivo fundamental de este estudio es demostrar que todos los cromatismos tienen una función armónica o tonal, existen seis casos puntuales que bien podrían ser denominados excepcionales debido a que implican notas cromáticas que no son parte de un acorde completo ni generan una nueva tonalidad. Sin embargo, estos seis únicos casos se entienden cono excepciones dentro de dyum de hs dr categorías ya expuestas: $\mathrm{CE}$ O CFT, ya que el tratamiento que evidencian no es el de un mera ornamentación melódica, sino que reflejan una intención acórdica incompleta o un movimiento escalístico dentro de una estructura diatónica específica. 


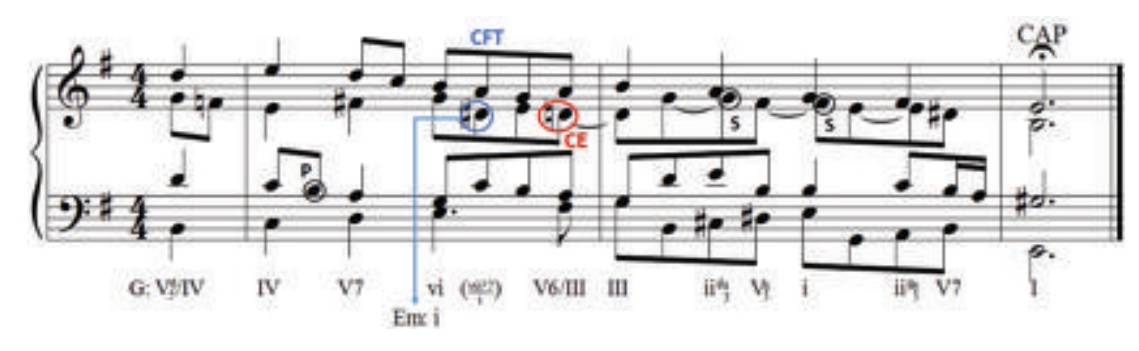

Gráfica 13. Frase final del coral 30 en mi menor

Al igual que en los dos ejemplos anteriores de cromatismo por salto, el intervalo involucrado es un tritono (contralto), lo cual implicaría un típico movimiento cromático hacia una sensible que cambiaría el centro tonal de sol mayor hacia mi menor (tonalidad del coral). Sin embargo, en el pulso siguiente, la misma voz ejecuta un re becuadro que parece evitar el giro a mi menor $y$, en cambio, ratificaría a sol mayor como centro por un par de acordes más (C. 10, T. 3-4). Pero el movimiento no termina con este acorde de sol mayor sino que se genera una secuencia que implica que el movimiento del bajo concluya verdaderamente en el mi del tercer tiempo; esta generación del módulo secuencial inicia con el acorde de dominante en 6 y concluye con la llegada a la cadencia en mi menor. De esta forma, parece más contundente considerar al re\# la nota que genera el cambio de centro tonal y al re natural un ce que hace énfasis al tercer grado en mi menor.

Además, existen otros fenómenos que oscurecen el pasaje y enfatizan la ambigüedad tonal: uno de ellos es la nota cromática que está acoplada a otras dos voces (soprano y tenor), las cuales conforman un vii ${ }^{\circ}$ de mi menor pero con el bajo en mi. Es decir, salvo por la voz inferior, que no se mueve, las otras sugieren una nueva armonía que redirecciona la escala de sol mayor a mi menor. Este tipo de movimiento no es único de este coral: en el coral 28 (gráfica 7) se muestra un fenómeno casi idéntico en donde las tres voces superiores crean un vii ${ }^{\circ}$ mientras el bajo permanece estático, pero en ese caso es claro que el acorde incompleto produce el cambio de tonalidad a través del CFT y no la dualidad que se presenta en este.

Así mismo, en el coral 30 la armonía sobre la que se produce este acorde incompleto es precisamente la tónica principal del coral (mi menor), la cual viene de una dominante de sol mayor que provoca una cadencia deceptiva, pero que sirve para que el coral regrese a su tónica original. Además, y no es un hecho menos importante, el acorde de mi menor se prolonga un poco más de lo que viene ocurriendo con el ritmo armónico del coral hasta el momento, y es enfatizado melódica y armónicamente por su propia sensible acoplada a otras voces. Finalmente, luego de la aparición de los acordes de dominante y tónica de sol mayor, el final de la frase está contundentemente dirigido hacia mi menor, hecho que se produce a través del uso de la escala melódica en el bajo, en el que esta vez no vuelve a presentarse ningún re natural. Así pues, y según este análisis, el re\# es un CFT.

Es claro que este análisis puede generar suspicacias, ya que parecería estar acomodando el pasaje a la teoría que aquí se propone; por lo tanto, vale la pena exponer una segunda posibilidad de razonamiento para entender el pasaje, según cual sol mayor prevalece hasta el primer tiempo del compás 11 y, por consiguiente, el re\# se consideraría un bordado incompleto cromático y se entendería como un cromatismo no estructural. Justo después se presenta un salto de sexta descendente en el bajo que redirecciona definitivamente el pasaje hacia mi menor, donde se hace la cadencia final del coral.

Aunque desde esta perspectiva este sería un caso excepcional, de alguna manera el re\# también podría ser considerado un anticipo de la tonalidad en la que termina la frase. Además, todos los fenómenos descritos para soportar la primera opción deben ser tenidos en cuenta también en este último caso, ya que esta nota cromática, considerada una mera nota ornamental, no parecería hacerle justicia a la manera y al cuidado con la que está siendo tratada y al plan general diseñado por Bach para este coral. Aquí el compositor parece haber propuesto esta dicotomía entre sol mayor y mi menor desde el inicio, debido a que los movimientos melódicos cadenciales que tiene el cantus implican llegadas hacia alguna de estas dos tonalidades. Este hecho se ve resaltado de forma extrema justamente en esta sección de la última frase, la cual bien podría considerarse la zona climática del coral. Así pues, sería posible concluir que este re\# es un Ce pero construido sobre una armonía ornamental, en donde su función principal es la de anticipar el regreso a la tonalidad principal del coral

El coral 77 en la mayor, In dich hab' ich gehoffet, Herr (gráfica 14), al igual que el anterior, presenta una nota cromática que permite conformar con tres voces un acorde disminuido (vii $/ \mathrm{V}$ ), el cual es la dominante de mi mayor; sin embargo, el inicio de la frase es ambiguo en cuanto a la estructura diatónica gobernante, ya que no aparece un acorde de dominante que clarifique la escala. Por lo tanto, no resulta fácil entender el fragmento en mi mayor debido a que la frase anterior hizo cadencia en re mayor y el inicio de esta parece sugerir más a la mayor que a mi mayor.

Dos cifrados diferentes podrían explicar la ambigüedad tonal de esta frase. En el primero, la frase iniciaría en la tonalidad de mi mayor y el re\# del tenor sería una nota de paso que ayudaría a ratificar a mi mayor como el centro tonal del inicio de la frase; después, el pasaje modularía a la mayor a través de la dominante que aparece al final de este mismo compás (re becuadro). La segunda opción sería cifrar la frase completamente en la mayor teniendo en cuenta dos fenómenos: primero, que la cadencia precedente fue en re mayor y, por lo tanto, existe una relación más cercana con la mayor que con mi mayor; y segundo, que los acordes involucrados, antes del re\#, son la mayor y mi mayor, los cuales parecen estar cumpliendo funciones de tónica y dominante, ya que el segundo presenta un movimiento melódico-armónico típico de la dominante, como es en el estilo la suspensión 4-3,y

además, viniendo de re mayor resulta claro que el acorde de mi mayor actúa como la nueva dominante que produce la modulación a la mayor. 
En este sentido, el re\# del tenor debe ser interpretado como un CE que está soportado en las voces superiores. Por lo tanto, este caso excepcional se cifraría como una dominante secundaria (viio/V) dentro de la mayor, pero que está sobre una nota pedal de $\mathrm{V}$.

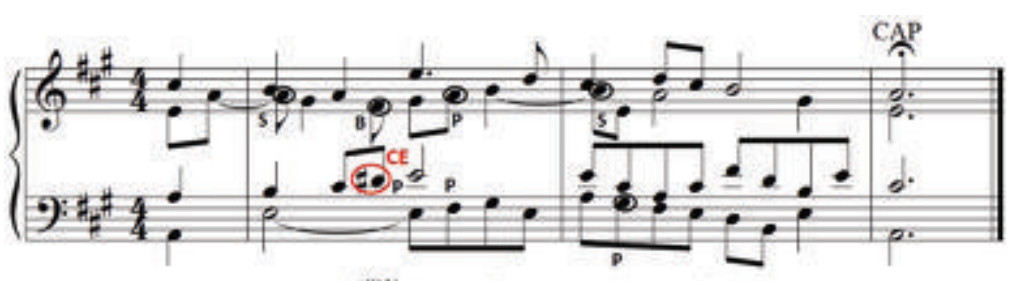

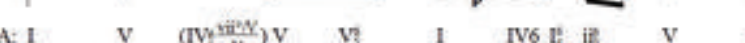

Gráfica 14. Frase final del coral 77 en mi menor

El siguiente caso excepcional ocurre en el coral 16 en si menor, Es woll' uns Gott genadig sein, el cual presenta un cromatismo que, en una primera mirada, sería entendido como una nota de paso cromática, ya que no forma parte de una estructura triádica, ni es una nota que sugiera un nuevo centro tonal (C. 14, T. 2, re\#). Así, su función parecería completamente melódica y se limitaría a enfatizar, cromáticamente, a la dominante en una llegada de semicadencia. Sin embargo, hay que anotar que, al igual que en los casos anteriores, si bien es solo el bajo el que se mueve melódicamente para crear el énfasis al $\mathrm{V}$ a través de este cromatismo, dos de las otras tres voces podrían pertenecer a la tríada del vii $/ \mathrm{V}$, donde solo una nota no pertenece al acorde (mi en el tenor).

Adicionalmente, la frase en cuestión presenta una serie de movimientos melódicos que implican sensibles a varios grados dentro de la tonalidad de la mayor. La primera sensible que aparece es precisamente re\#, la cua está en la segunda corchea del primer tiempo del compás 13, pero esta vez, aunque las otras voces no acompañan el movimiento, sí conforman un acorde que es una dominante secundaria (vii $6 / \mathrm{V}$ ). Luego, además de la sensible de la escala gobernante de la frase (la mayor), aparecen dos sensibles de si menor (tonalidad del coral) y al final, nuevamente, el re\#, pero esta vez como cromatismo de paso que imita, pero en el nivel del quinto, el movimiento melódico de la contralto: sol\#-la.

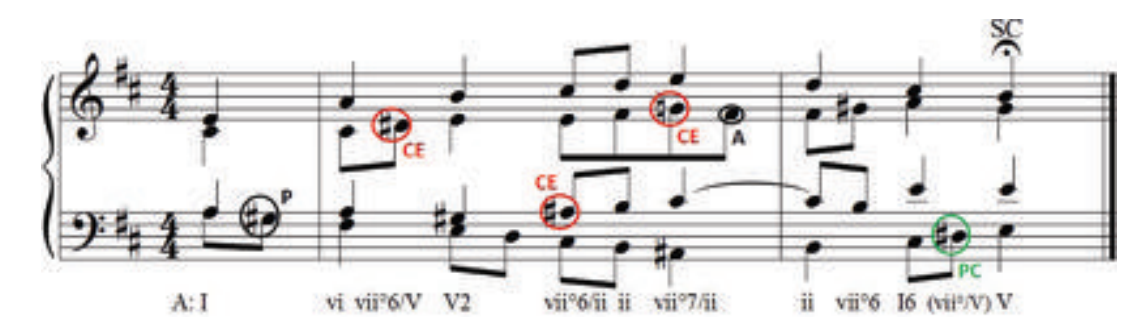

Gráfica 15. Sexta frase del coral 16 en si menor

De alguna manera, el uso de esta alteración refleja el cuidado que Bach tiene de los cromatismos, ya que implica la reiteración del primero que aparece al inicio de la frase y que hace parte de un acorde que podría considerarse la primera dominante del pasaje. Además, justo después de esta armonía, aparecen otras dos dominantes más: de la mayor y si menor, que evidencian la relativa inestabilidad tonal del pasaje, la cual es confirmada con la aparición del último cromatismo. Finalmente, la imitación melódica, aunada al hecho de que sí se configura parcialmente un acorde con tres de las voces, permite concluir que esta alteración puede ser interpretada como una excepción pero dentro del tipo CE (vii $/ \mathrm{V})$, en el que la nota del tenor (mi natural) se consideraría una suspensión que viene del acorde anterior y que anticipa el acorde final de la cadenci.
Otros corales que se asemejan a las excepciones expuestas son el 216 (cc. 14 y 17, t.2: re\#), el 343 (c. 9, t. 1: sol\#) y el 114 (c. 9, t. 3: do\#). Todos ellos parecen generar un acorde ornamental o falso acorde con otras voces en la segunda corchea, sin embargo, en el coral 216 los dos eventos ocurren después de las cadencias (sc), pero tres de las voces conforman un vii $7 / \mathrm{V}$ que sirve para prolongar el hecho cadencial mientras el bajo permanece estático. Por otro lado, el coral 343 no conforma un vii ${ }^{\circ}$ pero sí un $\mathrm{V}$ con las tres voces superiores. Y finalmente en el 114, el acorde es una dominante poco usual: tercero aumentado con séptima (IIIx7), que parece conformarse en una semicorchea; sin embargo, este caso podría asemejarse más a un CFT que a una excepción, ya que hay varios rasgos que permiten inferir que la tonalidad de la menor está desapareciendo para modular brevemente a re menor incluir su sensible.

Además de los casos anteriores, existen tres corales que, aunque pueden ser considerados excepcionales, sus características particulares y exclusivas impiden generar algún tipo de agrupación entre ellos. El primer caso es el del coral 338 en re mayor, Jesus, meine Zuversicht (gráfica 16: c. 4, t. 1: sib), donde el bajo genera un movimiento melódico cromático que enfatiza melódicamente a la dominante a través de la sensible inferior (solł) y la superior (sib). El problema es que el sib parece ser un simple ornamento melódico que sirve para convertir el acorde de sol mayor en menor dentro de re mayor. Sin embargo, a diferencia de otros casos parecidos, el movimiento del bajo no está acompañado por otra voz acoplada que permita confirmar la existencia de dos funciones armónicas distintas y no de una sola con un simple cambio de color o préstamo modal.

No existe en la colección de corales otro caso similar, ya que cuando ocurre este tipo de cromatismos por inflexión en los que solo una voz se mueve, la transformación suele ser de un acorde menor a uno mayor que genera una dominante secundaria a un grado de la escala Desde una mirada muy simplista, y aunque el caso podría reducirse a una rareza dentro de los cromatismos que conforman un acorde, es posible afirmar que la nota cromática hace parte de un acorde menor y, por lo tanto, se puede considerar un CE. Pero el caso resulta tan particular que para este estudio se ha categorizado como excepcional.

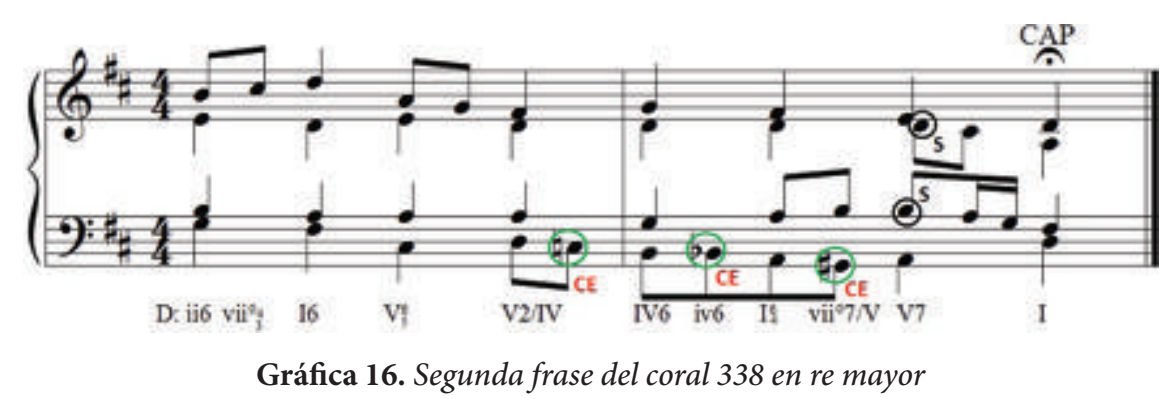

El segundo caso es el coral 351 en la mayor, Wenn mein Stündlein vorhanden ist (c. 4, t. 1), en el que se presenta un fenómeno particular en donde el mil de la contralto parece actuar como un CFT que al final de la frase no es ratificado, ya que en el pulso siguiente el tenor ejecuta un movimiento que niega cualquier intención de ir a fäl menor a través del uso del mi natural en un movimiento melódico ascendente (gráfica 17). Así la posibilidad de que mi\# sea el inicio de una nueva área tonal se frustra en favor de la tonalidad del coral: la mayor. Sin embargo, este evento cromático se enmarca dentro de un plan tonal en el que la mayor y fä meno están en constante discusión; de hecho, el mï ya ha aparecido al inicio de la primera frase como parte de un énfasis al sexto grado y está también en la tercera frase, en la que la tonalidad es justamente fä menor. Visto de este modo, el cromatismo en cuestión parece ser más bien una nota que hace parte de un juego en el que Bach utiliza la cercanía entre las dos tonalidades para generar ambigüedad tonal. Todo esto es producto de una melodía que no tiene movimientos melódicos que permitan hacer cadencias contundentes en la mayor o en fä menor, salvo en la última frase en la que hay una cadencia perfecta en la mayor. 


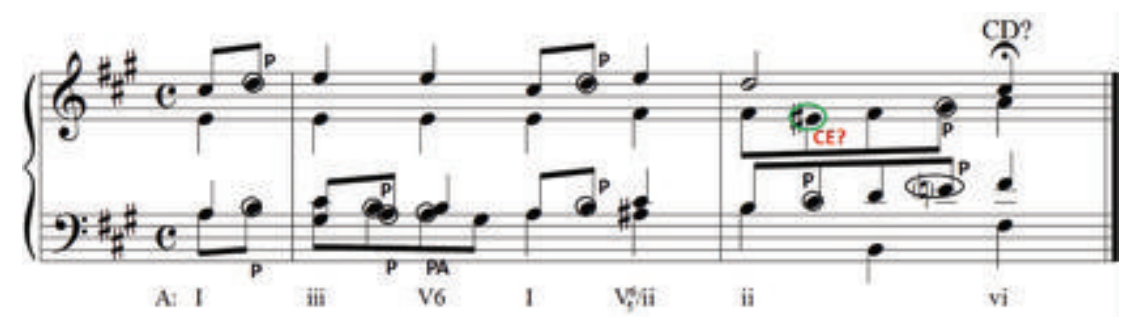

Gráfica 17. Segunda frase del coral 351

También es importante destacar que el mi\# en cuestión hace parte de una frase en la que el cierre cadencial no es claro, ya que, si se considera en la mayor, se entendería que hay un tipo de cadencia deceptiva bastante inusual: ii-V43-vi. Esta no solo sería inusual por la posición del acorde de dominante, sino porque el ii es prolongado durante un pulso y medio, y es en la corchea en donde aparece el V43 generado por unas notas de paso. Por otro lado, si se piensa que el fragmento está en fa\# menor debido a que el mi natural, de todas formas, pertenece a la escala menor natural, la cadencia involucraría un movimiento plagal en fa\# menor, que luego, en la siguiente frase, sería reafirmado con la cadencia imperfecta en esta tonalidad. En todo caso, es claro que este cromatismo está inmerso dentro de un proceso armónico y tonal bastante ambivalente en el que cualquiera de las dos opciones parece generar más dudas que certezas, por lo tanto, aunque aquí se considera el fenómeno excepcional, de alguna manera esta excepcionalidad cromática está fuertemente ligada a unos eventos melódicos, armónicos y tonales que son característicos y esenciales de este coral.

El último caso que aquí se presenta es el coral 205 en la menor, Herr Gott, dich loben wir, ejemplo que se considera completamente excepcional dentro de la teoría que se ha expuesto en este escrito sobre el uso del cromatismo en los corales de Bach. El hecho ocurre al final del compás 13 , en la anacrusa que da inicio a la frase 7 , en donde se presenta un fa natural que no pertenece a ningún acorde ni parece establecer una nueva área tonal (gráicica 18). En este caso, parecería que el fa natural es claramente una nota cromática de paso que no puede conectarse, en ningún sentido, a alguna de las dos categorías que aquí se exponen. Sin embargo, nuevamente esta excepcionalidad cromática, al igual que la del coral 351, parece estar ligada a una serie de particularidades en distintos niveles: primero, aunque el coral está en la menor, ya que la última cadencia así lo confirma, la realidad es que la melodía de la soprano desde el inicio del coral, tiene un movimiento que impide presentar con claridad a la menor. Además, el gesto final de la frase no permite hacer una cadencia perfecta en la menor debido a la repetición de la nota la en los dos pulsos finales de la frase; sin embargo, este hecho es aprovechado para hacer un gesto plagal en la menor, pero sin haber mostrado el acorde de dominante ni la sensible en ningún momento de la frase lo cual hace dudar sobre si la menor es el centro tonal del coral o si estamos frente a una frase en la que, debido a las características del cantus firmus, los fenómenos que se muestran son más modales que tonales.

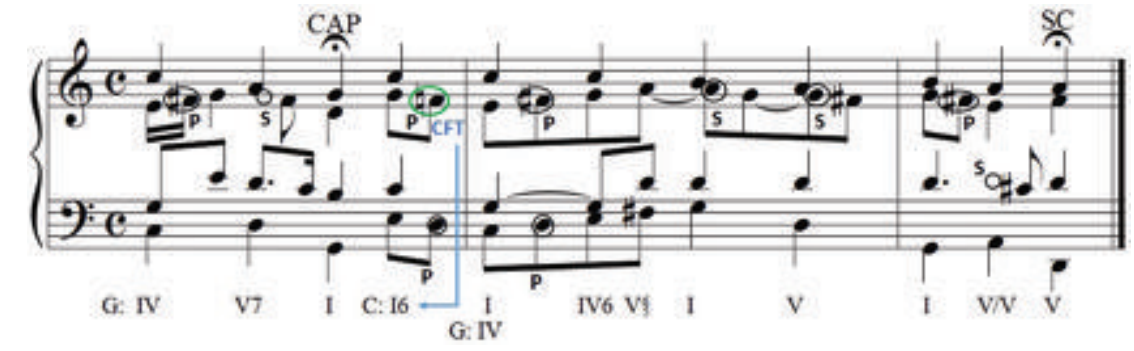

Gráfica 18. Coral 205, séptima frase

De igual forma que el hecho anterior, este coral presenta innumerables ejemplos tonales y armónicos que podrían considerarse extraños o inusuales dentro de la colección de corales. En este sentido, es importante anotar que es la melodía la que genera todos los inconvenientes, debido a que tiene muchos rasgos modales (do mayor). Así, la aparición del fa natural podría llegar a entenderse desde una mirada macro de este corl de casi 50 compes (el más largo de la coleccion), cono mirada maro de este cor decas 50 con alidades que están bastante alejadas de la tonalidad principal (sol mayor y re mayor).

Finalmente, toda la explicación de los casos que aquí se consideran excepcionales lo que busca es demostrar que no lo son tanto, ya que de alguna manera podrían encajar dentro de alguna de las categorías expuestas, y que su excepcionalidad se enmarca dentro de un panorama armónico y tonal mucho más grande de

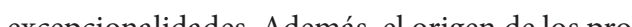
firmus, los cuales prese dentro de los procedimientos tonales que se manejaban en una época en la que se dio el tránsito del sistema modal y sus múltiples escalas, al sistema tonal, centrado en la relación armónica entre tónica y dominante.

Además, los pocos ejemplos excepcionales demuestran el cuidado con el que Bach utilizaba los cromatismos en su repertorio coral, implicando, en la mayoría de los casos, la conformación de una estructura armónica de dominante que tenía la función de enfatizar un grado de la estructura diatónica o de modular hacia un nuevo centro tonal. Por otro lado, todos los otros casos que no encajan en la primera categoría tienen una función tonal que busca reorganizar los grados de una escala en función de un redireccionamiento tonal a través de un evento melódico cromático, el cual, en ningún caso, puede considerarse meramente ornamental. A diferencia de otros compositores ${ }^{16} \mathrm{y}$ estilos (especialmente del Clasicismo Y Romanticismo), los corales de Bach demuestran que cada alteración de un grado

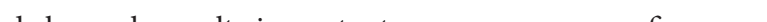
ya que todos los cros vertical (acorde) o a la transformación de una organización horizontal (escala).

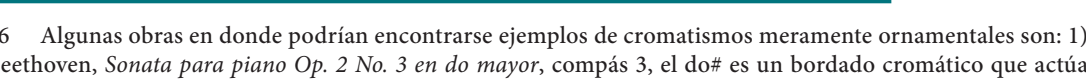

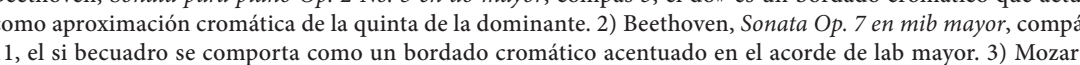

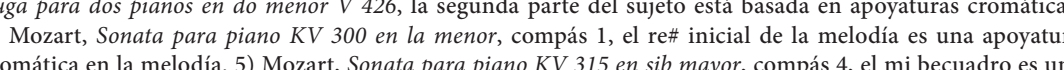

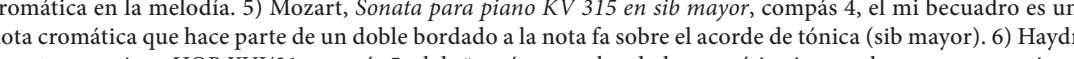

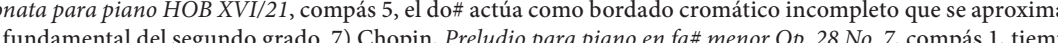
W fundamental del segundo grado. 7) Chopin, Preludio para piano en fat menor OP. 28 No. 7 , compás 1 , tiempo 


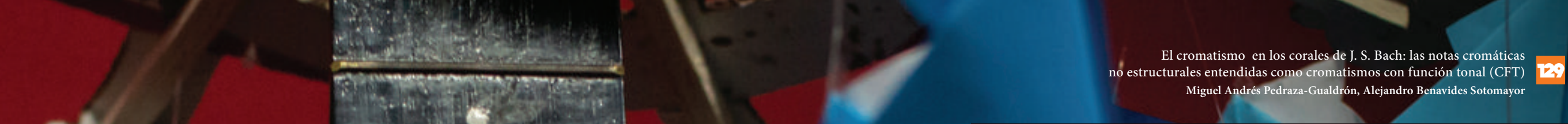

El futuro de este estudio está, por supuesto, en el abordaje de otro repertorio del mismo compositor, en el que se intuye con cierta seguridad que esta manera de abordar y entender el cromatismo no es propia solo de esta colección particular de piezas corales, sino que hace parte de la concepción general que tenía el compositor en relación con lo cromático, la cual debe verse reflejada en toda su obra y, especialmente, en aquellas piezas de gran envergadura como las cantatas, los preludios, las fugas, las suites, entre otras. Así, la ampliación de este estudio abordará las piezas para teclado con un alto trabajo contrapuntístico como las invenciones y las fugas, para luego analizar las obras orquestales de gran factura como los conciertos brandenburgueses y las cantatas. De allí surgirán unas conclusiones definitivas que darán cuenta del manejo general que tenía Bach del cromatismo en toda su obra.

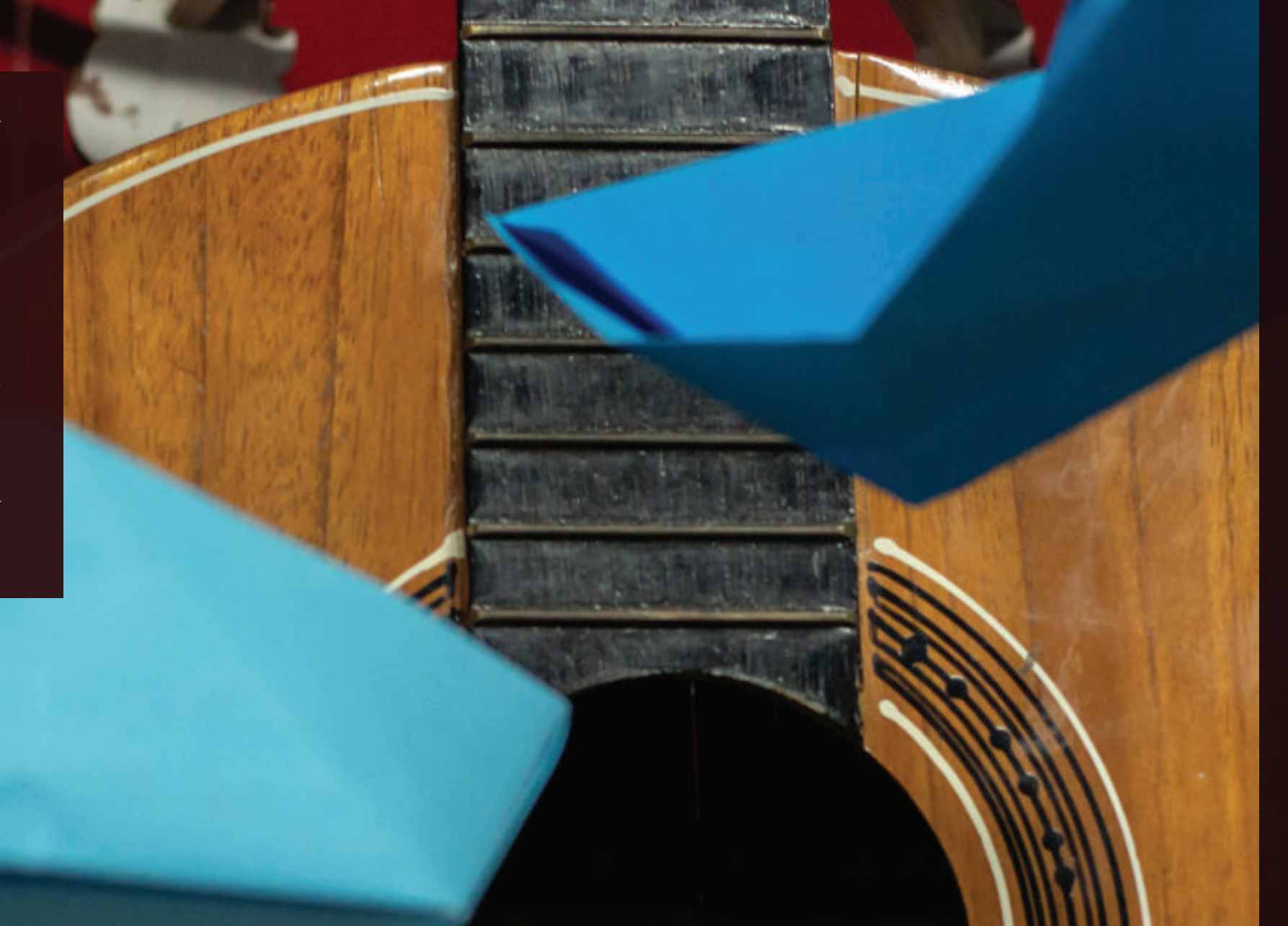

Referencias

Bach, J. S. (1870). 371 vierstimmige Choralgesänge. Wiesbaden: Breitkopf \& Härtel.

Bach, J. S. (1941). 371 harmonized chorales and 69 chorale melodies. Nueva York: Schirmer.

Bach, J. S. (1985). 389 chorales (Choral-Gesange): SATB (German Language Edition). Boca Raton: Kalmus Classic Edition

Bach, J. S. (2000). 371 four-part chorales. Vol. 2. Los Angeles: Alfred Music Publishing.

Bartel, D. (2003). Rhetoric in German Baroque music: ethical gestures. The Musical Times, 144(1885), 15-19.

Benjamin, T. (2004). The craft of tonal counterpoint. Nueva York: Routledge. Dunsby, J. y Whittall, A. (2014). Chromaticism. En A. Latham (Ed.), The Oxford Companion to Music. Oxford Music Online. Oxford University Press. Recuperado de http://www.oxfordmusiconline.com/ subscriber/article/opr/t114/e1396

Kennan, K. W. (1999). Counterpoint: based on Eighteenth-Century practice. Nueva Jersey: Prentice Hall.

Kostka, S. y Payne, D. (2004). Tonal harmony. Boston: McGraw-Hill. Mitchell, W. J. (1962). The study of chromaticism. Journal of Music Theory, 6(1), 2-31. Recuperado de www.jstor.org/stable/843257

Monlau, F. P. (1856). Diccionario etimológico de la lengua castellana. Madrid: Imprenta y Estereotipia de M. Rivadeneyra.

Rameau, J.-P. (1971). Treatise on harmony: (New English Transl.). Nueva York: Dover.

Riemann, H. (1930). Armonía y modulación. Ribera y A. R. Maneja (Trad.) Barcelona: Labor.

Schachter, C. y Aldwell E. (1989). Harmony and voice leading Orlando: Harcourt Brace Jovanovich.

Schonberg, A. (2004). Tratado de armonía. R. Barce (Trad). Madrid: Real Musical.

Willingham, T. (2013). The harmonic implications of the non-harmonic tones in the four-part chorales of Johann Sebastian Bach (tesis inédita de doctorado). Liberty University, Lynchburg, Virginia, Estados Unidos.

\section{Para citar este artícul}

Pedraza Gualdrón, M. A., y Benavides Sotomayor, A. (2019). El cromatismo en los corales de J. S. Bach: las notas cromáticas no estructurales entendidas como cromatismos con función tonal (CFT). (pensamiento), (palabra)... Y Obra. (23). https://doi.org/10.17227/ppo.num23-10360 